\title{
Pesquisa da Prevalência do Papilomavirus Humano em Amostras de Tecido Endometrial Normal e com Carcinoma pela Técnica de PCR
}

\author{
Search for Human Papillomavirus in Samples of Normal Endometrial Tissue and \\ Tissue with Carcinoma by the PCR Technique \\ Edison Natal Fedrizzi ${ }^{1}$, Newton Sérgio de Carvalho², Luisa Lina Villa ${ }^{3}$, \\ Irene Vieira de Souza $^{4}$, Ana Paula Martins Sebastião
}

\begin{abstract}
RESUM0
Objetivo: comparar a prevalência da presença do DNA do papilomavírus humano (HPV) pela técnica de PCR em amostras de tecido endometrial normal e com carcinoma endometrial de mulheres submetidas a tratamento cirúrgico (histerectomia) ou carcinoma endometrial e doença benigna.

Métodos: trata-se de um estudo observacional do tipo caso-controle onde foram avaliadas 100 mulheres (50 com endométrio normal e 50 com carcinoma endometrial) quanto a presença do DNA do HPV em amostra tecidual conservada em blocos de parafina, pelo método de PCR. Foram excluídos os casos de carcinoma endometrial cujo sítio primário da lesão era duvidoso ou com história prévia ou atual de lesões pré-neoplásicas ou carcinoma do trato genital inferior. Variáveis como idade, tabagismo, trofismo endometrial, diferenciação escamosa e grau de diferenciação tumoral foram também avaliadas.

Resultados: o risco relativo estimado da presença do HPV foi o mesmo nas mulheres com e sem carcinoma endometrial. O HPV foi detectado em 8\% dos casos de carcinoma e 10\% no endométrio normal. Apesar de o HPV ter sido detectado 3,5 vezes mais em mulheres fumantes no grupo sem carcinoma, não houve diferença estatística. A presença do HPV também não esteve correlacionada com a idade das mulheres, trofismo endometrial, diferenciação escamosa e grau de diferenciação tumoral. Os HPV 16 e 18 (5 dos casos com o tipo 16 e 4 com o tipo 18) foram os vírus mais freqüentemente encontrados, tanto no tecido endometrial normal, quanto no carcinomatoso. Nenhum vírus de baixo risco oncogênico foi detectado nas amostras.

Conclusão: o HPV está presente no tecido endometrial de mulheres com carcinoma endometrial na mesma proporção que nas com tecido endometrial normal, não se demonstrando a possível associação deste vírus no desenvolvimento do carcinoma endometrial.
\end{abstract}

PALAVRAS-CHAVE: Papilomavírus humano. HPV. Oncogênese. Carcinoma endometrial.

${ }^{1}$ Departamento de Ginecologia e Obstetrícia da Universidade Federal de Santa Catarina - Hospital Universitário, Florianópolis, SC, Brasil

${ }^{2}$ Departamento de Ginecologia e Obstetrícia da Universidade Federal do Paraná - Hospital de Clínicas, Curitiba, PR, Brasil ${ }^{3}$ Departamento de Virologia do Instituto Ludwig de Pesquisa sobre o Câncer, São Paulo, SP, Brasil

${ }^{4}$ Departamento de Patologia da Universidade Federal de Santa Catarina - Hospital Universitário, Florianópolis, SC, Brasil ${ }^{5}$ Departamento de Patologia da Universidade Federal do Paraná - Hospital de Clínicas, Curitiba, PR, Brasil

Correspondência:

Edison Natal Fedrizzi

Av. Governador José Boabaid 272

Jardim Anchieta - Bairro Córrego Grande

88037-200 - Florianópolis - SC

Fone/Fax: (48) 234-4891

e-mail: enfedrizzi@uol.com.br

\section{Introdução}

O carcinoma de endométrio é uma das afecções malignas de origem ginecológica mais comuns no mundo ocidental. Em muitos países, como nos EUA, é considerado o câncer ginecológico mais freqüente. São diagnosticados aproximadamente 150 mil novos casos por ano no mundo. As mais altas taxas anuais de incidência (acima de 15/100 mil mulheres) são encontradas na América do Norte, Europa e Nova Zelândia. Esta doença é menos comum (menos de 5/100 mil mulheres por ano) em partes da Ásia e Oriente Médio. No Brasil 
ocupa a quinta posição $(2,7 \%)$ entre todas as neoplasias diagnosticadas na mulher e a terceira de causa ginecológica (após o colo uterino e mama). A maior incidência anual é observada em São Paulo, com 14/100 mil mulheres/ano ${ }^{1}$.

$\mathrm{O}$ adenocarcinoma de endométrio é doença de mulheres de faixa etária mais alta, ocorrendo $75 \%$ dos casos nas pós-menopausadas. Entretanto, aproximadamente $25 \%$ dos casos são diagnosticados antes da menopausa e de 2 a $14 \%$ antes dos 45 anos. Os fatores de risco para esta neoplasia não são tão evidentes para estas mulheres mais jovens.

Silverberg et al. ${ }^{2}$, em 1972, constataram aumento na incidência do carcinoma adenoescamoso com maior agressividade, falta de resposta à radioterapia e menor sobrevida em cinco anos. Estudos sistemáticos realizados na década de 80 demonstraram diferentes características epidemiológicas, clinicopatológicas e moleculares nas mulheres portadoras do carcinoma endometrial, associadas à idade, tipo histológico e agressividade que, possivelmente, estão relacionadas a diferentes etiologias.

O carcinoma de endométrio compreende vários subtipos, cada qual com seu próprio padrão de comportamento e evolução. O adenocarcinoma endometrióide, também designado apenas adenocarcinoma, é o tipo mais comum (60-70\% dos casos) ${ }^{3}$. O adenoacantoma (10-20\%) e o carcinoma adenoescamoso (10\%) apresentam células escamosas associadas ao componente glandular. Nos adenoacantomas ou adenocarcinomas com metaplasia escamosa, o elemento escamoso parece citologicamente benigno e costuma ocorrer em tumores bem diferenciados. Por outro lado, os adenocarcinomas cujo elemento escamoso parece citologicamente maligno são designados como carcinomas adenoescamosos ou carcinomas mistos.

A incidência desta neoplasia é influenciada por muitos fatores de risco, particularmente por variáveis hormonais e reprodutivas. Obesidade, distúrbios do metabolismo dos carboidratos, menarca precoce, nuliparidade, infertilidade, ciclos anovulatórios, menopausa tardia, hipertensão e estrogenioterapia isolada são considerados fatores de risco. Em contrapartida, o uso de anticoncepcionais orais combinados ou componentes hormonais contendo progesterona tendem a diminuir estes riscos.

Curiosamente, um fator de diminuição do risco do carcinoma endometrial que merece destaque é o tabagismo. Lesko et al. ${ }^{4}$, em 1985, relataram, em mulheres na pós-menopausa, diminuição em $50 \%$ no risco deste câncer em fumantes de mais de 25 cigarros por dia. A nicotina exerce estí- mulo nas enzimas microssômicas oxidativas hepáticas, alterando a ligação do estrogênio aos receptores, além de inibir a conversão periférica de androgênios a estrogênios. A importância disso reside em que, nos casos de câncer do endométrio em fumantes, provavelmente haja menor dependência hormonal e conseqüentemente pior prognóstico, como ocorre com os carcinomas endometriais não hormônio-dependentes.

Com base neste perfil epidemiológico de associação a um componente hormonal, ganhou aceitação a hipótese de que a gênese da doença seria desencadeada pela acão proliferativa endometrial dos estrógenos sem o balanço promovido pela progesterona. Especificamente, os estudos sugerem que o tipo histológico mais comum (o adenocarcinoma endometrióide) evolui de um endométrio hiperplásico por ação estrogênica excessiva e geralmente apresenta evolução clínica lenta. Entretanto, este perfil de risco não explica todos os casos desta doença.

Em contraste, a minoria dos carcinomas endometriais, melhor representados pelos tipos serosos, não estão associados aos fatores hormonais citados anteriormente. Desenvolvem-se principalmente em endométrio inativo ou atrófico, com evolução clínica mais agressiva, em mulheres idosas ou em mulheres mais jovens sem os distúrbios hormonais anteriores. Baseados nisso, diversos autores têm proposto que há dois tipos de carcinoma endometrial: o tipo 1 (estrógeno-dependente) é geralmente representado pelo adenocarcinoma endometrióide, associado ao hiperestrogenismo e hiperplasia endometrial. Ocorre com maior freqüencia em mulheres mais jovens, nulíparas, obesas e hipertensas; é de baixo grau histológico, bem diferenciado, rico em receptores de estrogênio e progesterona, invade superficialmente o miométrio e apresenta metástases ganglionares infreqüentes, baixa mortalidade e baixo risco, sendo, portanto, de melhor prognóstico. A outra variante, conhecida como tipo 2 (não estrógeno-dependente), é principalmente representada pelo adenocarcinoma seroso, não estando associado com hiperestrogenismo ou hiperplasia. Ocorre geralmente em mulheres idosas, magras, multíparas e normotensas. É de alto grau histológico, geralmente indiferenciado, pobre em receptores hormonais, invade profundamente o miométrio, apresenta metástases ganglionares mais freqüentemente, e, portanto, é de pior prognóstico. O carcinoma tipo 1 está associado a uma mutação nos genes supressores tumorais PTEN e dos oncogenes ras, ao passo que o tipo 2 está associado à mutação de $p 53$.

Diferente do carcinoma do endométrio, já está bem estabelecida a relação do carcinoma 
epidermóide do colo uterino com a infecção pelo papilomavirus humano (HPV), presente em praticamente todos os casos. Evidências clínicas, epidemiológicas, morfológicas e de biologia molecular demonstram correlação importante entre o HPV e o desenvolvimento de lesões intra-epiteliais e invasoras do colo uterino.

Estudando seu mecanismo oncogênico, observa-se que as proteínas E6 e E7, produzidas pelos HPV de alto risco, são as responsáveis pela transformação maligna devido a sua habilidade em ligar-se e inativar as proteínas supressoras tumorais p53 e pRb do hospedeiro, respectivamente. Na minoria dos cânceres cervicais que não são infectados com o HPV (ou não são detectados por serem desconhecidos), o gene p53 é inativado provavelmente por uma mutação.

Inicialmente relacionado às lesões escamosas, recentemente o HPV 18 foi associado ao adenocarcinoma endocervical ${ }^{5-8}$. O adenocarcinoma do colo uterino atualmente representa cerca de $20 \%$ dos casos. Usando métodos de amplificação do DNA, como a reação em cadeia da polimerase (polymerase chain reaction - PCR), diversos autores encontraram tanto nos adenocarcinomas in situ como nos invasores, positividade variável (até $64 \%$ ), sendo alta a proporção do HPV do tipo 18 e menos freqüente dos tipos 16 e 33. Iwasawa et al. ${ }^{6}$ encontraram o DNA do HPV em $75 \%$ dos casos de adenocarcinoma (17\% HPV 16 e 56\% HPV 18) do colo uterino.

Muitas características biológicas das pacientes com adenocarcinoma de colo uterino são também encontradas em pacientes com adenocarcinoma de endométrio. Milsom e Friberg ${ }^{5}$ encontraram número significativamente maior de casos de diabetes e nuligestação (conhecidos fatores de risco para o carcinoma endometrial) em pacientes com adenocarcinoma de colo uterino, quando comparadas ao grupo de carcinoma epidermóide.

Por outro lado, vários estudos evidenciam a presença do HPV em lesões malignas extragenitais como boca, laringe, esôfago, intestino, pulmão, rim, conjuntiva, saco lacrimal, etc., demonstrando a capacidade deste virus de infectar outros tecidos além do trato genital inferior. Outros autores identificaram o HPV também na cavidade endometrial normal ${ }^{9-11}$.

Todas estas informações sugerem que é possível a presença do HPV em lesões endometriais, principalmente se levarmos em consideração o HPV 18, que apresenta capacidade infectante comprovada também para o epitélio glandular endocervical $^{8}$. A presença de seqüências de DNA do HPV no trato genital superior é ainda desconhecida, ou pelo menos muito pouco estudada. Poucos trabalhos avaliaram sua presença nos casos de adenocarcinomas ou adenoacantomas de endométrio ${ }^{12,13}$.

A idade também pode ser fator marcante na possível correlação entre HPV e carcinoma endometrial, uma vez que, atualmente, têm-se encontrado casos de adenocarcinoma endometrial em pacientes mais jovens, sem que o fator hormonal seja identificado como risco importante. Correlacionando com o colo uterino, Uchiyama et al. ${ }^{7}$ observaram que pacientes com adenocarcinoma de colo uterino e HPV (+) eram significativamente mais jovens que aquelas HPV (-).

Se avaliarmos as características biológicas e epidemiológicas do adenocarcinoma de colo uterino e endométrio, que são semelhantes, e o conhecimento atual de que as lesões cervicais glandulares estão associadas à infecção pelo HPV 16,33 e principalmente o 18 , podemos pensar na possibilidade de alguns casos de carcinoma endometrial também estarem relacionados à infecção por estes virus. Recentemente, alguns estudos têm pesquisado esta relação $0^{6-8,12,14}$.

Utilizando a técnica de PCR, vários autores têm encontrado o HPV no tecido endometrial com câncer, variando de $7 \%{ }^{15}$ até $37,5 \%{ }^{9}$. Outros autores $^{12,16}$, entretanto, não encontraram estes vírus nestes tecidos.

Concluindo, existem vários fatores clínicos, biológicos, epidemiológicos e genéticos que nos induzem a pensar na possibilidade de o HPV também estar relacionado com algumas lesões préinvasivas e invasivas do endométrio, entretanto esta ainda é uma questão que está longe de ser respondida.

Com a finalidade de contribuir para a compreensão da possível relação entre o HPV e o câncer de endométrio, este estudo comparou 2 grupos de mulheres (50 com carcinoma de endométrio e 50 sem carcinoma) quanto à presença do HPV em tecido endometrial, estudada pelo método de PCR em blocos fixados e conservados em parafina.

A avaliação da presença do HPV em mulheres com e sem carcinoma de endométrio poderá contribuir para esclarecer se este vírus está relacionado à etiologia desta doença e, portanto, se será preciso adotar novas estratégias de diagnóstico, prevenção e tratamento destas neoplasias.

\section{Pacientes e Métodos}

Trata-se de estudo observacional do tipo caso-controle, no qual o tamanho da amostra foi 
avaliado levando em consideração que, segundo a literatura, a prevalência do HPV no carcinoma de endométrio é cerca de $25 \%$ e no tecido endometrial normal inferior a 3\% (Lininger et al. ${ }^{13}$, 1998; O'Leary et al. ${ }^{14}$, 1998). Assumindo a razão de $1: 1$ no tamanho dos 2 grupos e aplicados ao cálculo padrão da amostra (Epi-Info 6,04), os resultados mostraram que uma amostra de 92 mulheres (46 com carcinoma e 46 sem carcinoma) seria adequada para uma avaliação com poder estatístico de $80 \%$ e intervalo de confiança de $95 \%(\mathrm{p}<0,05)$. Para tanto, analisamos 50 amostras de tecido endometrial com carcinoma e 50 de tecido endometrial normal.

Foram avaliadas 50 mulheres submetidas à histerectomia pelo Serviço de Ginecologia e Obstetrícia do Hospital Universitário da Universidade Federal de Santa Catarina, Hospital das Clínicas da Universidade Federal do Paraná e clínica privada, portadoras de carcinoma endometrial (grupo de casos) e 50 mulheres, também submetidas a histerectomia, portadoras de outras doenças (não malignas), com endométrio normal à histopatologia (grupo controle). O grupo de casos foi consituído de mulheres submetidas a tratamento cirúrgico por carcinoma endometrial, comprovado histologicamente. No grupo controle foram avaliadas mulheres submetidas a tratamento cirúrgico (histerectomia) por outras doenças, cuja avaliação pelo patologista demonstrou a presença de tecido endometrial normal.

Foram excluídos do grupo de casos as mulheres com diagnóstico de carcinoma endometrial cujo sítio primário da lesão era duvidoso, com a possibilidade de tratar-se de carcinoma de colo uterino ou órgão contíguo (bexiga, reto) com invasão endometrial, e as mulheres com história prévia ou atual de lesões pré-neoplásicas ou de carcinoma do trato genital inferior tratados ou não. Do grupo controle foram excluídos todos os casos em que havia a presença de lesão pré-neoplásica endometrial (hiperplasias endometriais) e do trato genital inferior e as mulheres que foram submetidas no passado a algum tratamento antineoplásico (radioterapia ou quimioterapia) para qualquer tipo de neoplasia.

Variáveis de controle como idade e tabagismo também foram avaliadas. Quanto à idade, as mulheres foram estratificadas em duas categorias: mulheres com idade $\leq 50$ anos (definido como as mulheres com idade inferior ou igual a 50 anos e 364 dias no dia da cirurgia) e mulheres com mais de 50 anos (definido como mulheres com idade superior ou igual a 51 anos no dia da cirurgia). Quanto ao hábito do tabagismo, as mulheres foram divididas em duas categorias: não fumantes (definidas como as mulheres que nunca fumaram ou que fumaram por um período inferior a 6 meses) e fumantes (definidas como as pacientes que fumam pelo menos 1 cigarro/dia ou que já fumaram por período superior a 6 meses).

Foram selecionados os 100 blocos de parafina mais representativos de tecido endometrial pelo mesmo patologista do Serviço de Anatomia Patológica do Hospital Universitário da Universidade Federal de Santa Catarina. Os dados referentes à idade das pacientes e tabagismo foram pesquisados nos prontuários do Serviço de Arquivo Médico dos referidos Hospitais e da clínica privada. A revisão dos casos quanto ao tipo histológico, diferenciação escamosa e grau de diferenciação tumoral foi de acordo com as normas da Sociedade Brasileira de Patologia $^{3}$. Os tipos histológicos foram classificados em endometrióide, adenoescamoso, pouco diferenciado, seroso, de células claras e misto. A diferenciação escamosa foi considerada quando algum componente escamoso (benigno ou maligno) esteve presente nos carcinomas. O grau de diferenciação tumoral (bem diferenciado, moderadamente diferenciado ou pouco diferenciado) foi avaliado tanto para o grau histológico (ou arquitetural) quanto para o grau citológico (ou nuclear).

Os blocos mais representativos foram analisados para a pesquisa do HPV, sem conhecimento do resultado histopatológico dos espécimes, pelo método de PCR no Instituto Ludwig de Pesquisa sobre o Câncer, em São Paulo ${ }^{17}$. O princípio das reações de PCR se baseou na repetição de ciclos de 3 etapas: 1) desnaturação do DNA: obtida mediante a brusca elevação da temperatura da amostra analisada para $95^{\circ} \mathrm{C}$, por um minuto. Neste momento ocorre a separação da "cadeia dupla" de DNA; 2) anelamento ou hibridização: ocorre entre a cadeia original de DNA (agora já desnaturada em "cadeia simples") e a seqüência de oligonucleotídeos que se liga à região inicial do DNA a ser amplificado, aumentando o número de cópias. Estes oligonucleotídeos são denominados "iniciadores" ou primers. A temperatura ótima para esta hibridização inicial varia de 37 a $70^{\circ} \mathrm{C}$, dependendo primariamente do comprimento dos primers e de sua sequência de oligonucleotídeos; 3) extensão: a extensão da seqüência de nucleotídeos em continuidade com a cadeia "iniciadora" mediada pela DNA-polimerase termoestável ocorre a $72^{\circ} \mathrm{C}$, por 1 a 2 minutos. Esta reação dá origem a cópias de nucleotídeos da matriz do DNA da amostra inicial, sendo ampliada a região limitada pelos dois extremos de ligação dos primers com a "matriz de DNA".

Este ciclo foi repetido 30 a 40 vezes, dando origem a um aumento do produto de amplificação 
conhecido como amplicon. Assim, ao final de $\mathrm{n}$ ciclos, a reação teve um número teórico máximo de $2^{\mathrm{n}}$ moléculas de DNA dupla fita, que são cópias exatas da região específica do DNA molde que foi codificado pelos iniciadores.

Este método permite detectar todos os tipos de HPV, em torno de 40, no casos dos espécimes provenientes da mucosa genital. Para identificação genérica da infecção utilizaram-se primers que levam a amplificação de seqüências gênicas comuns ao maior continente de tipos de HPV ("iniciadores genéricos" ou general primers), relacionadas às proteínas estruturais do capsídeo viral. Seguindo-se a amplificação das cópias de DNA viral, as partículas virais foram detectadas e identificadas (tipagem viral) pela técnica de hibridização dot blot, utilizando-se sondas específicas de HPV, marcadas pelo fósforo radioativo $\left({ }^{32} \mathrm{P}\right)$.

Após todas as peças serem testadas com primers genéricos, seguidos de hibridização, e primers específicos, foram considerados HPV positivos os casos em que apareceu sinal indiscutivel observado na hibridização dot blot a partir de produtos de amplificação por primers genéricos.

Os dados relevantes, obtidos pela análise dos prontuários dos Serviços de Arquivo Médico e Estatística (SAME) dos hospitais envolvidos na pesquisa, os relatórios revisados do patologista e os resultados do PCR do Instituto Ludwig de São Paulo foram incluídos no Instrumento para Coleta de Dados. Em seguida foi preparado um programa de entrada de dados, para permitir a digitação e arquivo dos mesmos em banco de dados em computador. Os dados do banco foram submetidos a testes de consistência utilizando programa específico antes de serem processados. Para processamento destes dados foi utilizado o programa estatístico Epi-Info 6 (Statcalc), e o teste estatístico foi realizado por meio do cálculo de risco relativo estimado (odds ratio) da presença do HPV nas amostras, pelo teste exato de Fisher com intervalo de confiança de 95\%.

Este estudo foi aprovado pelo Comitê de Ética em Pesquisa com Seres Humanos da Universidade Federal de Santa Catarina. Como se trata de estudo de peça histológica, o consentimento livre e esclarecido foi dispensado, conforme a Resolução 196 que orienta a ética em pesquisa em seres humanos. O cuidado ético fundamental neste caso foi manter em sigilo o nome das mulheres envolvidas na pesquisa. Para tanto, cada caso foi identificado no instrumento de coleta de dados apenas pelo número do prontuário, iniciais do nome e número do caso da pesquisa.
Resultados

O odds ratio (OR) para presença do HPV neste estudo, nas amostras de tecido endometrial, foi o mesmo nas mulheres portadoras de carcinoma endometrial, comparadas às amostras histológicas de mulheres sem câncer (OR=0,78, IC 95\%, 0, 16-3,66). Identificamos o HPV em $10 \%$ dos casos de tecido endometrial normal e em $8 \%$ dos casos de carcinoma (Tabela 1). Não houve diferença estatisticamente significativa quanto à presença do HPV em tecido endometrial de mulheres com ou sem carcinoma de endométrio ( 8 e $5 \%$, respectivamente) com idade igual ou inferior a 50 anos $(\mathrm{OR}=1,58$, IC 95\% 0,6-5,41). Estudando as mulheres com mais de 50 anos, observamos que o risco relativo estimado da presença do HPV foi menor nas portadoras de carcinoma de endométrio que nas normais (8 e 13\%, respectivamente), porém não resultando em diferença estatisticamente significativa $(O R=0,57$, IC 95\% 0,09-3,42). Considerando apenas as mulheres com carcinoma de endométrio verificou-se que a presença do HPV na amostra histológica foi a mesma entre as mulheres com idade $\leq 50$ anos e as com idade superior a 50 anos (8\%). Nas mulheres sem carcinoma, a presença do HPV foi 2,5 vezes maior nas mulheres com idade superior a 50 anos ( 5 vs 13\%), porém, esta diferença não foi significativa $(p=0,325)$.

Tabela 1 - Risco relativo estimado (odds ratio) da presença do papilomavírus humano (HPV), segundo o diagnóstico histológico do endométrio.

\begin{tabular}{|c|c|c|c|c|c|c|c|}
\hline \multirow[t]{3}{*}{ HPV } & \multicolumn{4}{|c|}{ Histologia endometrial } & \multirow[t]{3}{*}{ OR } & \multirow[t]{3}{*}{ IC $95 \%$} & $p^{*}$ \\
\hline & \multicolumn{2}{|c|}{ Carcinoma } & \multicolumn{2}{|c|}{ Normal } & & & \\
\hline & $\mathrm{n}$ & $\%$ & $\mathrm{n}$ & $\%$ & & & \\
\hline Negativo & 46 & 92 & 45 & 90 & 1,0 & & \\
\hline Positivo & 4 & 8 & 5 & 10 & 0,78 & $0,16-3,66$ & 1 \\
\hline Total & 50 & 100 & 50 & 100 & & & \\
\hline
\end{tabular}

*Teste exato de Fisher $(p=0,500)$.

NS= não significante

O risco relativo estimado (OR) para presença do HPV foi 5 vezes menor nas amostras de endométrio das mulheres com câncer que entre as sem câncer, considerando apenas as mulheres fumantes (OR=0,21, IC 95\% 0,01-4,06). Esse menor risco, entretanto, não chegou a atingir significação estatística (Tabela 2). No caso das mulheres não fumantes, o risco relativo estimado para presença do HPV foi praticamente o mesmo nas amostras de tecido das mulheres com carcinoma endometrial e nas amostras de tecido sem câncer (OR=1,22, IC 95\% $0,18-8,28$ ) (Tabela 3). Analisando apenas o grupo 
das portadoras de carcinoma endometrial, observamos que a presença do HPV foi muito semelhante nas mulheres fumantes (7\%) e nas não fumantes (9\%). No grupo das mulheres sem carcinoma, apesar de a presença do HPV ter sido 3,5 vezes maior nas fumantes (7 vs 25\%), esta diferença não foi estatisticamente significativa $(p=0,175)$.

Tabela 2 - Risco relativo estimado (odds ratio) da presença do papilomavírus humano (HPV) nas mulheres fumantes, segundo o diagnóstico histológico endometrial.

\begin{tabular}{|c|c|c|c|c|c|c|c|}
\hline \multirow[t]{3}{*}{ HPV } & \multicolumn{4}{|c|}{ Histologia endometrial } & \multirow[t]{3}{*}{ OR } & \multirow[t]{3}{*}{ IC 95\% } & \multirow[t]{3}{*}{$p^{*}$} \\
\hline & \multicolumn{2}{|c|}{ Carcinoma } & \multicolumn{2}{|c|}{ Normal } & & & \\
\hline & $\mathrm{n}$ & $\%$ & $\mathrm{n}$ & $\%$ & & & \\
\hline Negativo & 14 & 93 & 6 & 75 & 1,0 & & \\
\hline Positivo & 1 & 7 & 2 & 25 & 0,21 & $0,01-4,06$ & NS \\
\hline Total & 15 & 100 & 8 & 100 & & & \\
\hline
\end{tabular}

* Teste exato de Fisher $(p=0,268)$.

NS= não significante

Tabela 3 - Risco relativo estimado (odds ratio) da presença do papilomavírus humano (HPV) nas mulheres não fumantes, segundo o diagnóstico histológico endometrial.

\begin{tabular}{|c|c|c|c|c|c|c|c|}
\hline \multirow[t]{3}{*}{ HPV } & \multicolumn{4}{|c|}{ Histologia endometrial } & \multirow[t]{3}{*}{ OR } & \multirow[t]{3}{*}{ IC $95 \%$} & \multirow[t]{3}{*}{$p^{*}$} \\
\hline & \multicolumn{2}{|c|}{ Carcinoma } & \multicolumn{2}{|c|}{ Normal } & & & \\
\hline & $\mathrm{n}$ & $\%$ & $\mathrm{n}$ & $\%$ & & & \\
\hline Negativo & 32 & 91 & 39 & 93 & 1,0 & & \\
\hline Positivo & 3 & 9 & 3 & 7 & 1,22 & $0,18-8,28$ & NS \\
\hline Total & 35 & 100 & 42 & 100 & & & \\
\hline
\end{tabular}

*Teste exato de Fisher $(p=0,571)$.

NS= não significante

A porcentagem de amostras de tecido endometrial com HPV nos casos de carcinoma endometrial foi praticamente a mesma na presença e ausência de diferenciação escamosa (11 e 10\%, respectivamente).

Não observamos diferença quanto à freqüência de detecção do HPV quando avaliamos o grau de diferenciação nuclear ou arquitetural nas mulheres com carcinoma endometrial. Os casos de carcinoma endometrial grau nuclear I e grau nuclear II/III tiveram ambos a presença do HPV em $8 \%$. Avaliando o grau de diferenciação arquitetural, observamos a presença do HPV em $7 \%$ dos casos grau I e $12 \%$ dos casos grau II/III $(\mathrm{p}=0,513)$.

Nas mulheres sem carcinoma endometrial em que o HPV foi identificado, não observamos diferença estatística quando comparamos o trofismo endometrial, apesar de ter sido o dobro nos casos de endométrio tróficos (6 vs 12\%) $(\mathrm{p}=0,440)$.

Analisando o tipo de HPV identificado nas amostras, observamos que o 16 foi o mais encontrado (10\%). Entretanto, o tipo 18 isolado foi en- contrado apenas em tecido endometrial normal (6\%), ao passo que sua associação com o HPV 31 foi encontrada em um caso de endométrio com carcinoma (Tabela 4).

Tabela 4 - Risco relativo estimado (odds ratio) da presença do papilomavírus humano (HPV) em tecido endometrial, segundo o diagnóstico histológico e tipo viral.

\begin{tabular}{|c|c|c|c|c|c|c|c|}
\hline \multirow[t]{3}{*}{ HPV } & \multicolumn{4}{|c|}{ Histologia endometrial } & \multirow[t]{3}{*}{ OR } & \multirow[t]{3}{*}{ IC $95 \%$} & \multirow[t]{3}{*}{$p^{*}$} \\
\hline & \multicolumn{2}{|c|}{ Carcinoma } & \multicolumn{2}{|c|}{ Normal } & & & \\
\hline & $n$ & $\%$ & $\mathrm{n}$ & $\%$ & & & \\
\hline Nenhum & 46 & 92 & 45 & 90 & 1,0 & & \\
\hline 16 & 3 & 6 & 2 & 4 & 1,47 & $0,19-13,29$ & NS $(p=0,519)$ \\
\hline 18 & 0 & 0 & 3 & 6 & - & & NS $(p=0,129)$ \\
\hline $31+18$ & 1 & 2 & 0 & 0 & - & & NS $(p=0,510)$ \\
\hline Total & 50 & 100 & 50 & 100 & & & \\
\hline
\end{tabular}

${ }^{*}$ Teste exato de Fisher.

NS= não significante

\section{Discussão}

O papel dos HPV de alto risco, principalmente o 16 e 18, no carcinoma do colo uterino tem sido bem documentado, mas sua contribuição na carcinogênese de outras neoplasias ainda foi pouco estudada e é controversa. Os resultados deste estudo mostraram que o HPV está presente no tecido endometrial de mulheres com carcinoma de endométrio em percentual muito semelhante ao encontrado em tecido endometrial normal. O risco relativo estimado da presença do HPV no tecido endometrial de mulheres com carcinoma foi de 0,78. Nesta casuística, 8\% dos casos de carcinoma endometrial apresentaram DNA do HPV. Estes resultados são semelhantes aos encontrados por Fujita et al. ${ }^{15}$ que, apesar de terem avaliado número pequeno de casos, encontraram percentual de $7 \%$. Outros trabalhos, no entanto, encontraram indices bem maiores de positividade, com percentuais variando de 24 a 40\% ${ }^{9,11,13,14,18,19}$.

A maioria dos estudos, no entanto, não demonstrou a presença do HPV nos carcinomas endometriais $^{12,16}$. Resumo do percentual da presença do HPV em tecido endometrial normal e com carcinoma pode ser visto na Tabela 5 .

A identificação do DNA do HPV no trato genital superior (em alterações benignas e malignas) não é incomum e seu significado ainda é incerto $^{9-11,20}$.

A especificidade tecidual de infecção dos HPV, aparentemente exclusiva para o epitélio pavimentoso da pele e das mucosas, tem sido contestada nos últimos anos, pois vários trabalhos mostram a capacidade do HPV de infectar locais 
diferentes. Tseng et al. ${ }^{21}$ demonstraram a presença do HPV no líquido amniótico de mulheres grávidas e Hermonat et al. ${ }^{22}$ no sinciciotrofoblasto de abortos espontâneos. Estes achados evidenciam a capacidade do virus de infectar a cavidade uterina também, pelo que não deve surpreender o achado do vírus no endométrio.

Tabela 5 - Prevalência do DNA do papilomavírus humano (HPV) pela técnica de PCR em tecido endometrial normal e com carcinoma, de acordo com vários autores.

\begin{tabular}{|c|c|c|c|}
\hline \multirow[t]{2}{*}{ Autor } & \multirow[t]{2}{*}{ Ano } & \multicolumn{2}{|c|}{ HPV no endométrio (\%) } \\
\hline & & Normal & Câncer \\
\hline Milde-Langosch ${ }^{20}$ & 1993 & NA & 37,5 \\
\hline Lai et al. ${ }^{9}$ & 1992 & 70 & 37,5 \\
\hline Wong et al. ${ }^{10}$ & 1993 & 4,5 & NA \\
\hline Fujita et al. ${ }^{11}$ & 1995 & 13 & NA \\
\hline Fujita et al. ${ }^{15}$ & 1996 & NA & 7 \\
\hline Hachisuga et al. ${ }^{16}$ & 1996 & NA & 0 \\
\hline Zimna et al. ${ }^{18}$ & 1997 & NA & 30 \\
\hline Hording et al..$^{12}$ & 1997 & NA & 0 \\
\hline Lininger et al..$^{13}$ & 1998 & NA & 25 \\
\hline O'Leary et al..$^{14}$ & 1998 & 0 & 35 \\
\hline Semczuk et al. ${ }^{19}$ & 2000 & NA & 24 \\
\hline \multicolumn{4}{|l|}{ Fedrizzi et al. } \\
\hline (presente estudo) & 2004 & 10 & 8 \\
\hline Total & & 19,5 & 20,4 \\
\hline
\end{tabular}

$\overline{\mathrm{NA}}=$ não avaliada.

Nesta amostra encontramos DNA do HPV em $10 \%$ das mulheres com endométrio normal, sendo 2 vezes mais freqüente nos endométrios tróficos (12\%) que atróficos (6\%). A grande maioria dos autores, entretanto, não encontraram o DNA viral nestes casos ${ }^{14}$. Exceção é o trabalho de Lai et al. ${ }^{9}$, que encontraram DNA do HPV em 70\% dos casos de endométrio normal ou com alguma doença benigna.

O conceito de que o processo oncogênico do HPV esteja limitado ao trato genital inferior já não tem mais sustentação, pois também pode estar relacionado a tumores em localizações diferentes do trato genital e fora dele. Na década de 80 tivemos um relato de que os gens HPV E6 e E7 apresentavam habilidade para transformar células epiteliais superficiais do ovário humano, sugerindo que o HPV seja capaz de induzir neoplasia no trato genital feminino alto. Além disso, vários estudos tem monstrado a associação deste vírus com neoplasias malignas extragenitais como a boca, laringe, esôfago, intestino, pulmão, rim, conjuntiva e saco lacrimal, entre outros.
O adenocarcinoma de endométrio é tipicamente doença da mulher na pós-menopausa e aproximadamente $85 \%$ das pacientes têm mais de 50 anos de idade. Apesar de a incidência do adenocarcinoma de endométrio ter aumentado nos últimos anos, esta doença continua incomum nas pacientes na pré-menopausa ${ }^{23}$. Em mulheres jovens é geralmente associada a estádio inicial, bem diferenciado e de bom prognóstico. Se mulheres jovens com risco aumentado para o desenvolvimento do carcinoma endometrial pudessem ser identificadas e acompanhadas ou tratadas precocemente, teríamos uma modificação no prognóstico e incidência desta doença. Porém, os fatores de risco clássicos para o carcinoma endometrial não são encontrados nestas mulheres ${ }^{23,24}$. Paslov et al. ${ }^{23}$, analisando 237 mulheres com carcinoma endometrial e 538 controles, observaram que apenas o fator predisposição familiar foi significativo, com OR=2,1 (IC 95\% 1,1-3,8). Jeffery et al. ${ }^{24}$ observaram que $32 \%$ das mulheres com carcinoma endometrial abaixo de 45 anos apresentavam endométrio normal e funcionante. Daí a importância de se verificar se a infecção pelo HPV poderia ser um fator de risco neste grupo etário. Caso o HPV realmente esteja associado com esta neoplasia, a imunização pela vacina, atualmente em fase de testes, diminuiria significativamente o número de carcinoma endometrial nos próximos anos nestas pacientes.

Não encontramos diferença na presença do DNA do HPV de acordo com a idade das mulheres avaliadas. O percentual de positividade foi de $8 \%$ tanto no grupo com idade igual ou inferior a 50 anos, quanto no de idade superior a 50 . Estratificamos a amostra nestas 2 faixas para melhor avaliar os riscos da neoplasia endometrial em mulheres na pré e pós-menopausa, uma vez que a média de idade da menopausa das mulheres brasileiras é de $50 \operatorname{anos}^{25}$. A seleção de qualquer idade específica como ponto de corte para a menopausa é arbitrária, pois ela não ocorre na mesma época em todas as mulheres, mas um período semelhante para a maioria das mulheres é uma alternativa. Um fator importante a ser considerado é a diferença na faixa etária dos grupos, pois no grupo controle tivemos quase o dobro de mulheres com idade inferior ou igual a 50 anos (42 vs 24\%), podendo isto ter interferido nos resultados. Apesar de que nas mulheres sem carcinoma o HPV foi 2,5 vezes mais encontrado na faixa etária superior aos 50 anos, este achado, entretanto, não foi estatisticamente significativo.

O fumo tem sido considerado fator importante para o desenvolvimento da infecção pelo HPV e a evolução das lesões pré-cancerosas no colo 
uterino. Também tem sido associado com aumento no risco de câncer em vários locais e, em especial, para a mulher, nos órgãos genitais (vulva, vagina e colo). A nicotina e a cotinina, além de outros metabólitos do fumo, levariam a uma diminuição do número das células de Langerhans no trato genital inferior, resultando em diminuição da resposta imunológica, principalmente em face das infecções virais, como o HPV. Entretanto, temse discutido um possivel efeito protetor do tabagismo no desenvolvimento do câncer endometrial. A nicotina diminui o nível de estrógeno por uma inibição enzimática (aromatase) e o hábito de fumar parece reduzir a idade da menopausa em algumas mulheres. Vários estudos sugerem risco diminuído de câncer endometrial em mulheres tabagistas $^{4}$.

Procuramos identificar alguma relação entre a presença do DNA do HPV no tecido endometrial e o hábito de fumar. Avaliando apenas as fumantes, apesar de encontrarmos um risco relativo estimado da presença do HPV no endométrio com câncer cinco vezes menor do que nas mulheres com endométrio normal, esta diferença não foi significativa. A aparente dificuldade do HPV de se instalar em endométrio neoplásico em mulheres fumantes desaparece quando comparamos a presença do vírus em mulheres com câncer endometrial fumantes e não fumantes (7 e 9\%, respectivamente). É interessante porém, encontrarmos 3,5 vezes mais o DNA do HPV em tecido endometrial normal em mulheres tabagistas, apesar de esta diferença não ter sido significativa.

Stockwell e Lyman ${ }^{26}$ observaram que, quando as mulheres com carcinoma endometrial foram subdivididas por idade, houve uma diferença no fator proteção. Mulheres com idade inferior a 50 anos não apresentaram evidência da associação do fumo e risco de câncer, ao passo que as com idade maior tiveram clara evidência da diminuição do risco com o aumento do número de cigarros fumados por dia (mais de 40 cigarros/dia reduziu em 60\% a chance de ter câncer endometrial, quando comparadas às não fumantes). O mesmo resultado foi obtido por Smith et al. ${ }^{27}$, que mostraram que o tabagismo aumentava o risco em mulheres na pré-menopausa e diminuia na pósmenopausa em relação à incidência do carcinoma endometrial.

O papel do HPV na patogênese de lesões préinvasivas e invasivas do colo uterino tem sido extensivamente investigado e seu papel como agente etiológico está bem estabelecido. Vários tipos de HPV, especialmente o 16 e o 18 têm sido associados ao carcinoma epidermóide invasor do colo uterino. Recentemente o DNA do HPV tem também sido demonstrado nos adenocarcinomas cervicais $^{20,28}$. A positividade do HPV nos adenocarcinomas endocervicais varia de 15 a 85\%, com média de $57 \%{ }^{10}$. O HPV 16 é o tipo predominante nos casos de carcinoma epidermóide ou adenoescamoso, ao passo que o HPV 18 prevalece no adenocarcinoma cervical ${ }^{8}$. Todos os tipos de HPV isolados nos estudos que avaliaram a presença do vírus no carcinoma de endométrio e neste estudo foram os de risco oncogênico (principalmente o 16 e o 18). Encontramos mais freqüentemente o HPV 16 nos casos de carcinoma (75\%) e o HPV 18 nos endométrios normais (60\%). O HPV 31 esteve associado ao $18 \mathrm{em}$ apenas um caso de câncer. Entretanto, Czerwenka et al. ${ }^{29}$ detectaram alguns casos de HPV de baixo risco (6 e 11) em seu estudo.

Os adenocarcinomas endometriais freqüentemente apresentam focos de diferenciação escamosa benigna (adenoacantomas) ou maligna (carcinomas adenoescamosos). A origem deste epitélio ainda é desconhecida, mas O'Leary et al. ${ }^{14}$ acreditam que o HPV possa estar envolvido na gênese destes tecidos. Os autores encontraram aparente associação dos HPV de baixo risco (6 e 11) e metaplasia escamosa endometrial, encontrando HPV 6 em 22\% dos casos de adenoacantomas e questionam a possivel interação do HPV na patogenia da metaplasia escamosa extracervical. Em nosso estudo avaliamos esta possível associação mas não encontramos diferença, pois o HPV esteve presente em 11\% dos casos com diferenciação escamosa e em 10\% nos sem diferenciação, e todos os HPV isolados foram os de alto risco oncogênico. É possível que alguns casos de diferenciação escamosa não tenham sido identificados neste trabalho pela dificuldade de se avaliar o tumor em toda a sua extensão, uma vez que apenas alguns cortes de tecido neoplásico são estudados.

A diferença de percentual da presença do HPV no carcinoma endometrial encontrado nos diversos trabalhos pode ser devida à metodologia utilizada ou mesmo ao processamento do espécime para estudo. A amostra da maioria dos estudos foi com poucos casos e muitas vezes compararam adenocarcinoma de colo e endométrio com critérios mal definidos na sua diferenciação. As populações foram bastante distintas, com prevalências distintas também da infecção pelo HPV. Devemos considerar a possibilidade de vários pesquisadores não terem detectado a presença do HPV talvez por utilizarem técnicas menos sensiveis, como a hibridização dot blot ou Southern blot.

A PCR é a técnica mais sensivel para a detecção do DNA do HPV. Porém, o DNA extraído de 
tecido embebido em parafina é geralmente fragmentado ou danificado, impedindo, muitas vezes, sua correta identificação ${ }^{28}$. Também devemos considerar que pode haver resultados falso-positivos, principalmente em função de contaminação, o que não é raro pela técnica de PCR. Talvez isto possa ter ocorrido com Lai et al. ${ }^{9}$, que encontraram percentual bastante elevado da presença do HPV tanto em tecido endometrial normal como no tecido com carcinoma.

Vários fatores podem ter interferido nos diferentes índices de positividade do HPV nos estudos anteriores, como a escolha do método de detecção, diferentes fatores de risco não avaliados (fumo, número de parceiros sexuais, baixo nível socioeconômico, interação com outras DST) e o próprio delineamento do estudo.

Após a revisão da literatura, acreditamos que este seja o primeiro estudo do tipo caso-controle que inclui um número de pacientes com poder estatístico suficiente para análise. O tamanho da amostra necessária para um poder estatístico de $80 \%$ com intervalo de confiança de 95\% levando em consideração a positividade do HPV para o grupo de casos de $25 \%$ e para o grupo controle de $3 \%$ calculado demonstrou a necessidade de 92 casos (46 doentes e 46 sadios), satisfazendo as necessidades para análise. Até o momento encontramos apenas um trabalho na literatura que compara a presença do HPV em tecido endometrial normal com carcinoma, porém com um grupo controle muito pequeno de 10 casos, todos HPV negativos ${ }^{14}$. Várias limitações metodológicas dificultam a avaliação de um número maior de casos, tanto pela doença não ser tão freqüente, quanto pelas dificuldades em selecionar mulheres com características semelhantes e o alto custo do exame de PCR. Esperávamos encontrar número maior de casos positivos para o HPV no endométrio de mulheres portadoras de carcinoma, mas provavelmente fatores como uma avaliação de grupos muito heterogêneos (diversos tipos histológicos, mulheres com distintas faixas etárias, peso e alterações hormonais) possam ter interferido nos resultados. É possivel que tenhamos algum resultado diferente se avaliarmos grupos de mulheres com características semelhantes, como por exemplo, amostras de um só tipo de neoplasia, determinadas populações, ou, como ocorre no câncer de colo uterino, mulheres com alguns co-fatores específicos.

Definitivamente o HPV está presente no tecido endometrial e a maioria dos estudos demonstram que os tipos de alto risco oncogênico são os mais prevalentes. Gual o seu verdadeiro papel neste local ainda desconhecemos. Caso novos tra- balhos demonstrem uma estreita correlação do HPV com o carcinoma endometrial, teremos modificações importantes no acompanhamento das mulheres portadoras desta infecção, assim como uma mudança na forma de triagem desta neoplasia. $\mathrm{O}$ advento atual de novas e eficazes drogas antivirais como o interferon recombinante $\mathrm{e}$ a vacina anti-HPV poderia modificar substancialmente o tratamento e número de casos de carcinoma endometrial no futuro.

Até o momento todos os trabalhos a respeito de carcinoma de endométrio se referem ao desequilíbrio hormonal feminino, com predomínio da ação estrogênica, como sendo responsável pela oncogênese. Entretanto, esta hipótese não explica todos os casos, principalmente os que ocorrem em pacientes mais jovens, sem os fatores de risco conhecidos. Nem mesmo as novas teorias isoladas das alterações nos genes PTEN, ras e p53 explicam todos os casos. Estas alterações nos genes supressores tumorais estão associadas a outros fatores que desconhecemos até o momento e em que talvez o HPV possa ser um dos envolvidos. A relação causal entre o HPV e o carcinoma endometrial necessita mais estudos, incluindo um que satisfaça o "postulado de Koch," no qual um agente etiológico isolado e desenvolvido em cultura seja capaz de reproduzir a doença se inoculado em cobaias experimentais, e os "critérios de Bradford-Hill" para inferência causal ${ }^{30}$.

Concluindo, nossos resultados mostram que a hipótese de o HPV estar envolvido na gênese de alguns casos de carcinoma endometrial não se confirmou. Existem, porém, vários fatores clínicos, biológicos, epidemiológicos e genéticos que nos levam a pensar na possibilidade de o HPV também estar relacionado com as lesões préinvasivas e invasivas do endométrio, ou seja: os fatores de risco do adenocarcinoma do colo uterino, em que os HPV 16 e 18 são freqüentemente isolados, são semelhantes ao do endométrio, os adenocarcinomas endometriais freqüentemente apresentam padrão escamoso associado (metaplasia escamosa ou carcinoma epidermóide), e é sabido o tropismo do HPV 16 para este tipo de epitélio. A presença do $\operatorname{HPV}(16,18$, 33) está atualmente bem definida também nas lesões glandulares do colo uterino (adenocarcinoma in situ e invasor). A presença do HPV no líquido amniótico de pacientes grávidas, fora do trabalho de parto, comprovando a capacidade do HPV de se localizar também na cavidade uterina. Ocorrência do HPV em outras neoplasias, distantes da área genital, como orofaringe, traquéia, pulmão, esôfago, intestino, rins, conjuntiva e saco lacrimal, consenso que existem dois tipos 
de carcinoma endometrial, um hormônio-dependente (estrógeno) e outro não hormônio-dependente, cujo mecanismo oncogênico ainda é pouco conhecido e está associado a alterações nos genes supressores tumorais. Os genes E6 e E7 dos HPV de alto risco atuam sobre os genes supressores tumorais $p 53$ e $p R b$ no colo uterino. A expressão exagerada e a mutação de p53 são freqüentemente encontradas no carcinoma endometrial. O carcinoma de vulva também apresenta dois tipos distintos de tumores, o relacionado à infecção pelo HPV e mais freqüente em mulheres jovens (tipo bowenóide) e o não relacionado à infecção pelo HPV e acometendo mais mulheres idosas (tipo basalóide), podendo esta associação também estar presente no carcinoma endometrial. Há trabalhos recentes na literatura demonstrando casos de carcinoma endometrial associados à presença do HPV. Acreditamos, portanto, que o papilomavírus humano possa ser o responsável pelo menos por alguma fase da carcinogênese de alguns tipos de carcinoma endometrial que não estão associados ao perfil hiperestrogênico. Esperamos que novos estudos sejam realizados neste sentido, conhecendo melhor a história natural do carcinoma endometrial, esclarecendo o real papel do HPV no endométrio, permitindo melhorar nossa capacidade diagnóstica e manejar de forma mais adequada estas mulheres.

\section{ABSTRACT}

Objective: to compare the prevalence of DNA of human papillomavirus (HPV), in samples of normal endometrial tissue, and tissue with endometrial carcinoma of women submitted to surgical treatment (hysterectomy), or between endometrial carcinoma and benign disease, through the PCR technique.

Methods: this is an observational control-case study where 100 women (50 with endometrial carcinoma and 50 with normal endometrial tissue) were analyzed for the detection of HPV DNA in samples of endometrial tissue kept in paraffin blocks by the PCR technique. The cases of endometrial carcinoma with uncertain primary site of the lesion as well as the cases with previous or current history of pre-neoplasic lesions or carcinoma of the lower genital tract were excluded. Variables as age, smoking habit, endometrial trophism, squamous differentiation and degree of tumor differentiation were also evaluated.

Results: the estimated relative risk of the presence of HPV in the endometrial carcinoma and in the normal endometrial tissue was the same. HPV was detected in $8 \%$ of the cases of carcinoma and $10 \%$ in the normal endometrial tissue. In spite of HPV having been 3.5 times more detected in women with smoking habit in the group without carcinoma, there was no statistical difference. The presence of HPV was also not correlated with the women's age, endometrial trophism, squamous differentiation and degree of tumor differentiation. The HPV types 16 ( 5 cases) and 18 (4 cases) were the viruses most frequently found both in the normal endometrial tissue or in the tissue with carcinoma. No oncogenic low risk virus was detected in the samples.

Conclusion: The same proportion of HPV is present in the endometrial tissue of women with endometrial cancer and with normal endometrium. It could not be demonstrated a possible correlation of DNA of HPV with the development of endometrial carcinoma.

KEYWORDS: Human papillomavirus. HPV. Carcinogenesis. Endometrial carcinoma.

\section{Agradecimentos}

Os autores agradecem a colaboração e contribuição dos Drs. Aníbal Faúndes, Josué Lopes de Souza, Lee F-Ching e Sérgio Ossamu Ioshii.

\section{Referências}

1. Mirra AP, Franco EL. Cancer incidence in São Paulo, Brazil. São Paulo: Ludwig Institute for Cancer Research; 1985. (LICR Monograph Series in Cancer Epidemiology, 1).

2. Silverberg SG, Bolin MG, DeGiorgi LS. Adenoacanthoma and mixed adenosquamous carcinoma of the endometrium. A clinicopathologic study. Cancer 1972; 30:1307-14.

3. Bacchi CE, De Almeida PCC, Franco M. Manual de padronização de laudos histopatológicos Sociedade Brasileira de Patologia. $2^{\mathrm{a}}$ ed. Rio de Janeiro: Reichmann \& Affonso; 1999.

4. Lesko SM, Rosenberg L, Kaufman DW, et al. Cigarrette smoking and the risk of endometrial cancer. N Engl J Med 1985; 313:593-6.

5. Milsom I, Friberg LG. Primary adenocarcinoma of the uterine cervix. A clinical study. Cancer 1983; 52:942-7.

6. Iwasawa A, Nieminen P, Lehtinen M, Paavonen J. Human papillomavirus DNA in uterine cervix squamous cell carcinoma and adenocarcinoma detected by polymerase chain reaction. Cancer 1996; 77:2275-9.

7. Uchiyama M, Iwasaka T, Matsuo N, Hachisuga T, Mori M, Sugimori H. Correlation between human papillomavirus positivity and p53 gene 
overexpression in adenocarcinoma of the uterine cervix. Gynecol Oncol 1997; 65:23-9.

8. Lee $\mathrm{MF}$, Chang $\mathrm{MC}, \mathrm{Wu} \mathrm{CH}$. Detection of human papillomavirus types in cervical adenocarcinoma by the polymerase chain reaction. Int $\mathrm{J}$ Gynaecol Obstet 1998; 63:265-70.

9. Lai CH, Hsueh S, Lin CY, et al. Human papillomavirus in benign and malignant ovarian and endometrial tissues. Int J Gynecol Pathol 1992; 11:210-5.

10.Wong WS, Wong YF, Tam OS, Tam JS. Detection of human papillomavirus (HPV) in paraffin-embedded tissues of endometrial carcinoma. Aust N Z J Obstet Gynaecol 1993; 33:180-2.

11.Fujita M, Shroyer KR, Markham NE, et al. Association of human papillomavirus with malignant and premalignant lesions of the uterine endometrium. Hum Pathol 1995; 26:650-8.

12.Hording U, Daugaard S, Visfeldt J. Adenocarcinoma of the cervix and adenocarcinoma of the endometrium: distinction with PCR-mediated detection of HPV DNA. APMIS 1997; 105:313-6.

13.Lininger RA, Wistuba I, Gazdar A, et al. Human papillomavirus type 16 is detected in transitional cell carcinoma and squamotransitional cell carcinomas of the cervix and endometrium. Cancer 1998; 83:521-7.

14.O'Leary JJ, Landers RJ, Crowley M, et al. Human papillomavirus and mixed epithelial tumors of the endometrium. Hum Pathol 1998; 29:383-9.

15.Fujita M, Enomoto T, Wada H, Inoue M, Okudaira Y, Shroyer KR. Application of clonal analysis. Differential diagnosis for synchronous primary ovarian and endometrial cancers and metastatic cancer. Am J Clin Pathol 1996; 105:350-9.

16.Hachisuga T, Matsuo N, Iwasaka T, Sugiori H, Tsuneyoshi M. Human papillomavirus and p53 overexpression in carcinomas of the uterine cervix, lower uterine segment and endometrium. Pathology 1996; 28:28-31.

17.Villa LL. Biologia molecular: conceitos e principios básicos. In: Martins NV, Pereyra EAG, editores. Conhecendo o HPV. $1^{\text {a }}$ ed. São Paulo: Frontis; 2000. p. 137-43.

18.Zimna K, Poreba E, Kedzia W, Gozdizicka-Jozefiak A, Kedzia H. Human papillomavirus (HPV) in upper genital tract carcinomas of women. Eur J Gynaecol Oncol 1997; 18:415-7.
19.Semczuk A, Stenzel A, Baranowski W, et al. Detection of human papillomavirus types 16 and 18 in human neoplastic endometrium: lack of correlation with established prognostic factors. Oncol Rep 2000; 7:905-10.

20.Milde-Langosch K, Schreiber C, Becker G, Loning T, Stegner HE. Human papillomavirus detection in cervical adenocarcinoma by polymerase chain reaction. Hum Pathol 1993; 24:590-4.

21.Tseng CJ, Lin CY, Wang RL, et al. Possible transplacental transmission of human papillomaviruses. Am J Obstet Gynecol 1992; 166:35-40.

22.Hermonat PL, Kechelava S, Lowery CL, Korourian S. Trophoblasts are the preferential target for human papillomavirus infection in spontaneously aborted products of conception. Hum Pathol 1998; 29:170-4.

23.Paslov M, Lidegaard O, Klintorp S, et al. Risk factors among young women with endometrial cancer: a Danish case-control study. Am J Obstet Gynecol 2000; 182:23-9.

24.Jeffery JD, Taylor R, Robertson DI, Stuart GC. Endometrial carcinoma occurring in patients under the age of 45 years. Am J Obstet Gynecol 1987; 156:366-70.

25.Ferreira JAS. A perimenopausa. In: Fernandes CE, De Melo NR, Wehba S, editores. Climatério Feminino: fisiopatologia, diagnóstico e tratamento. $1^{\text {a }}$ ed. São Paulo: Lemos Editorial; 1999. p.?

26.Stockwell HG, Lyman GH. Cigarette smoking and the risk of female reproductive cancer. Am J Obstet Gynecol 1987; 157:35-40.

27.Smith EM, Sowers MF, Burns TL. Effects of smoking on the development of female reproductive cancers. J Natl Cancer Inst 1984; 73:371-6.

28. Matsuo N, Iwasaka T, Hayashi Y, Hara K, Mvula M, Sugimori H. Polymerase chain reaction analysis of human papillomavirus in adenocarcinoma and adenosquamous carcinoma of the uterine cervix. Int J Gynaecol Obstet 1993; 41:251-6.

29. Czerwenka K, Lu Y, Heuss F, Manavi M, Kubista E. Human papillomavirus detection of endometrioid carcinoma with squamous differentiation of the uterine corpus. Gynecol Oncol 1996; 61:210-4.

30.Franco EL. Epidemiologia das verrugas anogenitais e do câncer. Clin Obstet Am Norte 1996; 3:581-606. 